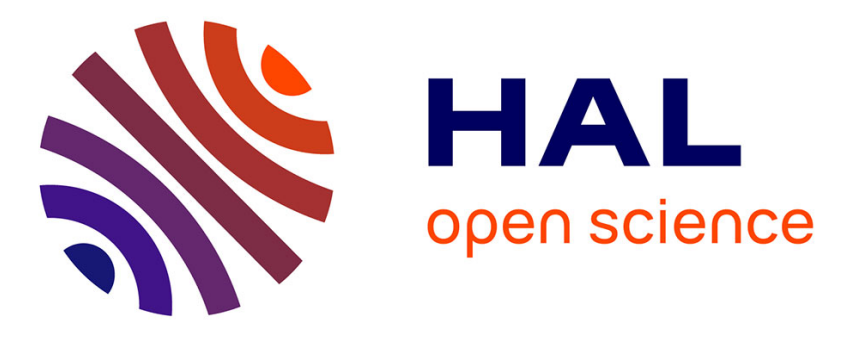

\title{
Finite element modelling of nearly incompressible materials and volumetric locking: a case study
}

Pierre-Yves Rohan, Claudio Lobos, Mohammad Ali Nazari, Pascal Perrier, Yohan Payan

\section{- To cite this version:}

Pierre-Yves Rohan, Claudio Lobos, Mohammad Ali Nazari, Pascal Perrier, Yohan Payan. Finite element modelling of nearly incompressible materials and volumetric locking: a case study. Computer Methods in Biomechanics and Biomedical Engineering, 2014, 17 (Issue sup1), pp.192-193. 10.1080/10255842.2014.931682 . hal-01061380

\section{HAL Id: hal-01061380 \\ https://hal.science/hal-01061380}

Submitted on 7 Sep 2014

HAL is a multi-disciplinary open access archive for the deposit and dissemination of scientific research documents, whether they are published or not. The documents may come from teaching and research institutions in France or abroad, or from public or private research centers.
L'archive ouverte pluridisciplinaire HAL, est destinée au dépôt et à la diffusion de documents scientifiques de niveau recherche, publiés ou non, émanant des établissements d'enseignement et de recherche français ou étrangers, des laboratoires publics ou privés. 


\title{
Finite Element modelling of nearly incompressible materials and volumetric locking: a case study
}

\author{
Pierre-Yves Rohan*†, Claudio Lobos $\neq$, Mohammad Ali Nazari§, Pascal Perrier and Yohan Payan $\uparrow$ \\ † TIMC-IMAG, UMR CNRS 5525, Université Joseph Fourier, 38706 La Tronche, France \\ †DI, Universidad Técnica Federico Santa María, Av. Vicuña Mackenna 3939, Santiago, Chile \\ $\checkmark$ Gipsa-lab, UMR CNRS 5216, Grenoble-INP \& University Grenoble Alpes, Grenoble, France \\ $\S$ Mechanical Engineering Depart. Faculty of Engineering, University of Tehran, Tehran, Iran
}

Keywords: Finite Element Simulation, incompressibility, locking, hourglass

\section{Introduction}

Finite element analysis of problems involving incompressible or nearly-incompressible materials at large strains is common in solid biomechanics since soft tissues are known to have high water content. However, these studies are often severely limited due to volumetric locking, a condition of excessive non-realistic stiffness which results from interpolation errors (Fung and Tong, 2001). Increasing the order of shape functions generally reduces volumetric locking but does not allow to fully deal with the problem of incompressibility.

Many numerical approaches have been proposed in the literature to address this issue. Among the most popular ones are the mixed formulation (Brezzi and Fortin, 1991), the underintegrated elements and the B-bar/F-bar methods. These methods have proved to be very efficient in dealing with incompressibility. However, they also present a certain number of drawbacks. For example, the reduced integration procedure may introduce spurious zero energy deformation modes in hexahedral elements, also known as hourglass instabilities, and often requires specialized schemes to stabilize the problem.

In the biomechanical community, the use of finite element models as research tools has grown exponentially during the last years. However, attention to the numerical aspects listed above have not kept pace with the general use of finite element modelling and are generally overlooked (Burkhart et al., 2013).

The purpose of this paper was therefore to illustrate the influence of the choice of the finite element technology on the occurrence of locking and hourglass instabilities. We chose to focus on the case study of the activation of the posterior genio-glossus (GGp) that is a lingual muscle located at the root of the tongue and inserts in the front to the mandible. The activation of this muscle compresses the tongue in the lower part and generates a forward and upward movement of the tongue body, because of the incompressibility of tongue tissues (for example during the production of the phonemes /i/ or /s/).

\section{Methods}

a. The tongue model

A 3D biomechanical model of the tongue is developped in ANSYS (figure 1(a)), based on the pioneer work of (Buchaillard et al., 2009). The same dataset and mechanical properties for passive tissues (including inactive muscles) are used (Mooney-Rivlin model with parameters $\mathrm{C}_{10}=1037$ $\mathrm{Pa}, \mathrm{C}_{20}=486 \mathrm{~Pa}$ and bulk modulus $\mathrm{K}=2.10^{7} \mathrm{~Pa}$ ).

Muscle activation is modelled using the Finite Element (FE) formulation of the Hill muscle model proposed by (Blemker et al., 2005). This model was implemented using the USERMAT functionality of ANSYS.

A MATLAB script is developped to automatically select in the mesh the elements belonging to the GGp and to define the fiber direction in each element (figure 1(b)). The total volume of this set of elements is specifically controlled in such a way that it remains constant regardless of the FE discretisation (tolerance $\pm 5 \%$ ).

Encastre boundary conditions are enforced on the bottom nodes of the model to simulate very roughly the role of the mouth floor and the attachments to the mandible.

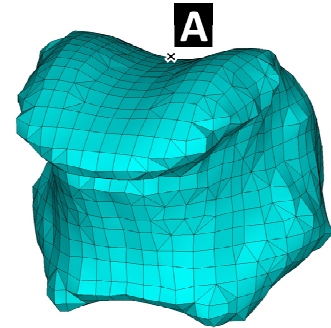

(a)

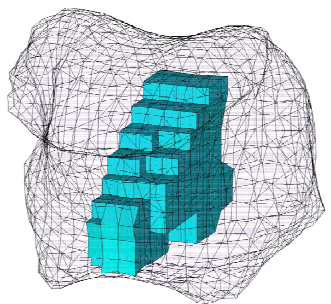

(b)
Figure 1 (a) 3D biomechanical model of the tongue (b) GGp muscle controlled by muscle activation.

b. Comparison between meshes

The biomechanical response of the tongue model to GGp activation is studied. A parametric study is conducted to evaluate the sensitivity of the tongue response to:

$\rightarrow$ The type of finite element used for the discretisation (pure tetrahedral mesh vs mixed tetrahedral/hexahedral mesh). 
$\rightarrow$ The order of the interpolation shape functions (First order solid285/solid187 4-node tetrahedrals and solid185/solid186 8-node hexahedrals vs second order solid187 10-node tetrahedrals and solid186 20-node hexahedrals).

$\rightarrow$ The integration method in hexahedral elements (i.e. full integration method $v s$ reduced integration method).

A convergence test is performed on both the pure tetrahedral and mixed tetrahedral / hexahedral meshes with standard first order elements showing that further mesh refinement produces a negligible change in the solution.

\section{Results and Discussion}

a. Salient qualitative results

The norm of the displacement vector (in $\mathrm{mm}$ ) of a point on the tongue groove (node A on figure 1(a)) is extracted. The results are listed in Table 1 below.

\begin{tabular}{|c|c|c|c|c|}
\hline ANSYS elements & $\begin{array}{c}\text { Element } \\
\text { formulation }\end{array}$ & $\begin{array}{l}\text { Integration } \\
\text { type }\end{array}$ & $\begin{array}{c}\text { Tetrahedral } \\
\text { mesh }\end{array}$ & $\begin{array}{l}\text { Mixed } \\
\text { mesh }\end{array}$ \\
\hline \multirow[t]{2}{*}{$\begin{array}{l}\text { Solid187 4-node } \\
\text { tetrahedral }\end{array}$} & \multirow[t]{2}{*}{$\begin{array}{l}\text { Pure displ. } \\
\text { formulation }\end{array}$} & $\begin{array}{l}\text { Reduced } \\
\text { integration }\end{array}$ & $n / a$ & 8,6 \\
\hline & & $\begin{array}{c}\text { Full } \\
\text { integration }\end{array}$ & 6.1 & 8,6 \\
\hline \multirow{2}{*}{$\begin{array}{l}\text { Solid186 8-node } \\
\text { hexahedral }\end{array}$} & \multirow[t]{2}{*}{$\begin{array}{l}\text { Mixed u-P } \\
\text { formulation }\end{array}$} & $\begin{array}{c}\text { Reduced } \\
\text { integration }\end{array}$ & $n / a$ & 8.8 \\
\hline & & $\begin{array}{c}\text { Full } \\
\text { integration }\end{array}$ & 6.1 & 8.8 \\
\hline \multirow{2}{*}{$\begin{array}{l}\text { Solid285 (mixed } \\
\text { u-P version) } 4- \\
\text { node tetrahedral }\end{array}$} & \multirow[t]{2}{*}{$\begin{array}{l}\text { Pure displ. } \\
\text { formulation }\end{array}$} & $\begin{array}{l}\text { Reduced } \\
\text { integration }\end{array}$ & $n / a$ & 15,8 \\
\hline & & $\begin{array}{c}\text { Full } \\
\text { integration }\end{array}$ & $n / a$ & 11,7 \\
\hline \multirow{2}{*}{$\begin{array}{l}\text { Solid185 8-node } \\
\text { hexahedral } \\
\text { (hourglass control } \\
\text { for reduced int.) }\end{array}$} & \multirow[t]{2}{*}{\begin{tabular}{|c|} 
Mixed u-P \\
formulation
\end{tabular}} & $\begin{array}{c}\text { Reduced } \\
\text { integration }\end{array}$ & $n / a$ & 15.8 \\
\hline & & $\begin{array}{c}\text { Full } \\
\text { integration }\end{array}$ & 9.6 & 15.3 \\
\hline \multirow[t]{4}{*}{$\begin{array}{l}\text { Solid187 8-node } \\
\text { tetrahedral }\end{array}$} & \multirow[t]{2}{*}{$\begin{array}{l}\text { Pure displ. } \\
\text { formulation }\end{array}$} & $\begin{array}{c}\text { Reduced } \\
\text { integration }\end{array}$ & $n / a$ & 13,8 \\
\hline & & $\begin{array}{c}\text { Full } \\
\text { integration }\end{array}$ & 13.6 & 13.8 \\
\hline & \multirow[t]{2}{*}{$\begin{array}{l}\text { Mixed u-P } \\
\text { formulation }\end{array}$} & $\begin{array}{c}\text { Reduced } \\
\text { integration }\end{array}$ & $n / a$ & 14,1 \\
\hline & & $\begin{array}{c}\text { Full } \\
\text { integration }\end{array}$ & 13.7 & 14,1 \\
\hline
\end{tabular}

Table 1 Displacement in millimeters at node A of the tongue in response to GGp muscle activation.

\section{b. Discussion}

Our results show that both tetrahedral and hexahedral standard pure-displacement first order elements (solid187/solid186) exhibit volumetric locking. With second order elements however (i.e. with mid-side nodes), the displacement is more important $(+60 \%$ increase $)$ and the results are comparable to those obtained with the mixed u-P formulation (13.8 mm versus $14.1 \mathrm{~mm}$ in the mixed mesh). This indicates that second order elements are effective in dealing with volumetric locking.

A computationally more efficient strategy to avoid volumetric locking is to use a reduced integration scheme. Our results however show that, in spite of the hourglass control algorithm implemented in solid185 first order elements, these tend to be excessively flexible $(15.8 \mathrm{~mm})$. Careful examination of the deformed mesh showed the presence of the characteristic "hourglass" shape in some elements, confirming that the hourglass control algorithm implemented in ANSYS is not efficient in preventing the apparition of hourglass instabilities. We therfore recommend that careful attention be paid to this possibility.

Finally, changing the element formulation (from pure displacement to mixed $\mathrm{u}-\mathrm{P}$ ) is computationally more expensive (10 times more) but the increase in accuracy is limited $(+2 \%)$.

\section{Conclusions}

The numerical difficulties of performing a FE analysis of quasi-incompressible materials are illustrated in this case study. Our results show that the choice of element technology has a significant influence on the appearance of volumetric locking and highlight the importance of running appropriate sensibility studies to ensure correct accuracy of the results. More precisely, to avoid volumetric locking, we strongly suggest to avoid using standard pure-displacement first order elements and, especially, tetrahedral elements (where volumetric locking was the most important). Where possible, we recommend the use of second order elements. If this is not possible, we recommend the use of a mixed tetrahedral/hexahedral mesh.

\section{Acknowledgments}

The authors would like to thank the EcosConicyt C11-E01, the Fondecyt de Iniciación 11121601, the University Joseph Fourier and Grenoble INP via the Grenoble Innovation Research grant (AGIR) and the Fondation pour la Recherche Médicale for their kind financial support.

\section{References}

Blemker S.S, Pinsky P.M, Delp S.L. 2005. A 3D model of muscle reveals the causes of nonuniform strains in the biceps brachii. $\mathrm{J}$. Biomech. 38, 657-665.

Brezzi F, Fortin M. 1991. Various Examples, in: Brezzi, F., Fortin, M. (Eds.), Mixed and Hybrid Finite Element Methods, Springer Series in Computational Mathematics. Springer New York, pp. 133-176.

Buchaillard S, Perrier P, Payan Y, 2009. A biomechanical model of cardinal vowel production: muscle activations and the impact of gravity on tongue positioning. J. Acoust. Soc. Am. 126, 2033-2051.

Burkhart T.A, Andrews D.M, Dunning C.E. 2013. Finite element modeling mesh quality, energy balance and validation methods: A review with recommendations associated with the modeling of bone tissue. J. Biomech. 46, 1477-1488.

Fung Y, Tong P. 2001. Classical and Computational Solid Mechanics. World Scientific. 